\title{
Manejo integrado da brusone em arroz no plantio direto e convencional(1)
}

\author{
Gisele Barata da Silva( ${ }^{(2)}$, Anne Sitarama Prabhu ${ }^{(3)}$ e Francisco José Pfeilsticker Zimmermann ${ }^{(3)}$
}

Resumo - O objetivo deste trabalho foi desenvolver medidas adequadas para o manejo da brusone (Pyricularia grisea), integrando a resistência da cultivar, práticas culturais e o controle químico. Foram realizados dois experimentos no campo, um no plantio direto (PD) e outro no plantio convencional (PC), nos anos agrícolas 1998/1999 e 1999/2000. Os tratamentos, num total de 16, em esquema fatorial $2^{4}$, consistiram de duas cultivares, Carajás e Primavera, duas doses de N, 30 e $60 \mathrm{~kg} \mathrm{ha}^{-1}$, sementes não tratadas e tratadas com fungicida pyroquilon e parcelas sem pulverização e com duas pulverizações, na parte aérea das plantas, da mistura dos fungicidas benomyl e difenoconazole. A incidência e a severidade da brusone nas folhas e nas panículas foram significativamente menores no PD em relação ao PC. A cultivar Primavera apresentou maior suscetibilidade à brusone nas folhas, independentemente do sistema de plantio. A dose de $60 \mathrm{~kg} \mathrm{ha}^{-1}$ de $\mathrm{N}$ contribuiu para aumento da brusone nas folhas, no PD e no PC, no segundo ano. As pulverizações com a mistura de fungicidas reduziram a severidade da brusone nas panículas nos dois sistemas de plantio. A produtividade foi maior no PC do que no PD e a cultivar Carajás foi superior à Primavera.

Termos para indexação: Oryza sativa, Pyricularia grisea, sistema de cultivo, controle químico.

\section{Integrated rice blast disease management under direct drilling and conventional tillage}

Abstract - The objective of this work was to develop adequate measures for rice blast (Pyricularia grisea) management integrating cultivar resistance, cultural practices and chemical control. Two field experiments were carried out, one under direct drilling and the other one under conventional tillage, during two consecutive rice growing seasons, 1998/1999 and 1999/2000. The treatments totaling 16, in a factorial scheme $2^{4}$, included two cultivars, Carajás and Primavera, two levels of N, 30 and $60 \mathrm{~kg} \mathrm{ha}^{-1}$, non-treated seed and seed treated with pyroquilon, plots non-sprayed and sprayed with two applications of fungicide mixture benomyl and difenoconazole. The incidence and severity of leaf and panicle blast were significantly lower under direct drilling as compared to the conventional tillage. The cultivar Primavera showed greater leaf blast susceptibility, independently of the tillage system. The application of $60 \mathrm{~kg} \mathrm{ha}^{-1}$ of $\mathrm{N}$ increased leaf blast in the second year. Two applications of fungicide reduced panicle blast severity in both tillage systems. The grain yield under conventional tillage was higher than under direct drilling. The cultivar Carajás was superior to Primavera.

Index terms: Oryza sativa, Pyricularia grisea, cropping systems, chemical control.

\section{Introdução}

A capacidade do solo da região dos Cerrados em manter a produtividade, em monocultivo de arroz de terras altas, é reduzida a partir do segundo ano de

(1) Aceito para publicação em 4 de setembro de 2002 .

Extraído da dissertação de mestrado apresentada pela primeira autora à Universidade Federal de Goiás (UFG), Goiânia, GO.

(2) UFG, Escola de Agronomia, Caixa Postal 131, CEP 74001-970 Goiânia, GO. E-mail: gibarata@bol.com.br

(3)Embrapa-Centro Nacional de Pesquisa de Arroz e Feijão, Caixa Postal 179, CEP 75375-000 Santo Antônio de Goiás, GO. E-mail: prabhu@cnpaf.embrapa.br, fjpz@cnpaf.embrapa.br exploração. A produtividade no primeiro ano chega a $2.255 \mathrm{~kg} \mathrm{ha}^{-1}$, passando a $1.789 \mathrm{~kg} \mathrm{ha}^{-1}$ no segundo ano (Silveira et al., 1998).

O plantio direto tem sido cada vez mais adotado pelos produtores da região dos Cerrados e, atualmente, a área plantada nesse sistema representa no Brasil mais de seis milhões de hectares, sendo aproximadamente dois milhões nos Cerrados. No Brasil Central, atualmente a produção de grãos de milho, de milheto ou sorgo na safrinha é obtida mediante plantio direto (Encontros..., 1998). Essa prática de cultivo objetiva reduzir custos e diminuir a erosão, via permanência dos restos culturais sobre o solo 
(Derpsch, 1998). Contudo, muitos agentes fitopatogênicos podem sobreviver nos restos culturais dos anos anteriores, ocasionando alta incidência de doenças (Reis, 1988; Fernandes \& Oliveira, 1997). As manchas causadas por Phaeosphaeria maydis, Exserohilum turcicum, Bipolares maydis em milho são doenças favorecidas pelo plantio direto por causa do ciclo de vida saprofítico (Fernandes \& Oliveira, 1997). Na soja cultivada em plantio direto, os restos culturais deixados sobre a superfície do solo contribuem para o aumento da fonte de inóculo de Diaporthe phaseolorum f. sp. meridonalis na área, provocando elevada severidade do cancro-dahaste (Yorinori, 1996).

Entre as principais enfermidades do arroz de terras altas, a brusone causada por Pyricularia grisea (Cooke) Sacc. ocupa o primeiro lugar. Não há informações quanto à influência do plantio direto sobre a incidência da brusone e, conseqüentemente, na produtividade e na qualidade de grãos.

O objetivo deste trabalho foi desenvolver medidas adequadas para o manejo da brusone, integrando a resistência da cultivar, práticas culturais e o controle químico.

\section{Material e Métodos}

Foram realizados dois experimentos no campo, um em plantio direto (PD) e outro em plantio convencional (PC) durante a safra 1998/1999, e repetidos na safra 1999/2000, na Fazenda Capivara, da Embrapa-Centro Nacional de Pesquisa de Arroz e Feijão. A área, em pousio nos três últimos anos, foi cultivada com a sucessão soja e milho para produção de grãos, e a seguir realizado o plantio de arroz por um ano.

Na safra 1998/1999 o arroz foi semeado em 15 de dezembro de 1998 e na safra 1999/2000, em 21 de janeiro de 2000, em ambos os sistemas de plantio. Em PC, a área foi preparada com uma aração profunda seguida de duas gradagens, nos dois anos de plantio. Em PD, na primeira safra, o arroz foi semeado sobre a palha do milheto plantado no dia 10 de setembro de 1998 e na segunda, sobre a palha do milheto plantado no dia 20 de outubro de 1999, sendo ambos dessecados com o herbicida glifosato (980 $\mathrm{g} \mathrm{ha}^{-1}$ de i.a.).

Na safra 1999/2000 observou-se ocorrência do bichobolo (Euethola humilis Burmeiter) na área de PD. Por esta razão, foi feita nova semeadura do arroz tanto no PD como no PC. O controle preventivo do bicho-bolo foi realizado por pulverização com o inseticida fipronil $\left(446,4 \mathrm{~g} \mathrm{ha}^{-1}\right.$ de i.a.), com volume de calda de $558 \mathrm{~L} \mathrm{ha}^{-1}$. Nessa safra, ambos os experimentos apresentaram deficiência de $\mathrm{Ne}$ de $\mathrm{Fe}$, os quais foram corrigidos pela aplicação de $66 \mathrm{~kg} \mathrm{ha}^{-1}$ de N (sulfato de amônia) e de três aplicações de sulfato ferroso, na dose de $6 \mathrm{~kg} \mathrm{ha}^{-1}$, com volume de calda de $400 \mathrm{~L} \mathrm{ha}^{-1}$.

O solo, classificado como Latossolo Vermelho distrófico, apresentava as seguintes características químicas (0-20 cm), na safra 1998/1999, no PD: pH 6,3; em $\mathrm{cmol}_{\mathrm{c}} \mathrm{dm}^{-3}: \mathrm{Ca}^{2+}, 3,03 ; \mathrm{Mg}^{2+}, 1,55 ; \mathrm{P}, 2,31 ; \mathrm{K}, 114,88$; $\mathrm{Cu}, 2,43 ; \mathrm{Fe}, 43,25$ e Mn, 37,75; e 17,5 $\mathrm{g} \mathrm{kg}^{-1}$ de MO; no PC: pH 5,1; em $\mathrm{cmol}_{\mathrm{c}} \mathrm{dm}^{-3}: \mathrm{Ca}^{2+}, 2,13 ; \mathrm{Mg}^{2+}, 1,41$; P, 2,46; K, 107,3; Cu, 2,26; Fe, 43,57 e Mn, 38,86; e $2,07 \mathrm{~g} \mathrm{~kg}^{-1}$ de MO.

O delineamento experimental foi o de blocos ao acaso, em esquema de parcelas subdivididas, com três repetições na safra 1998/1999 e quatro na safra 1999/2000. Os tratamentos aplicados às parcelas, totalizando 16 , em esquema fatorial $2^{4}$, foram constituídos das combinações entre duas cultivares, Carajás e Primavera; duas doses de $\mathrm{N}, 30$ e $60 \mathrm{~kg} \mathrm{ha}^{-1}$; sementes tratadas e não tratadas com o fungicida pyroquilon ( $\mathrm{g} \mathrm{kg}^{-1}$ de i.a.); e subparcelas sem pulverização e com duas pulverizações, na parte aérea das plantas, da mistura dos fungicidas benomyl $\left(500 \mathrm{~g} \mathrm{ha}^{-1} \mathrm{de}\right.$ i.a.) e difenoconazole (75 $\mathrm{g} \mathrm{ha}^{-1}$ de i.a.). Na safra 1998/ 1999, cada parcela foi composta por dez linhas de $16 \mathrm{~m}$ de comprimento, espaçadas em $0,35 \mathrm{~m}$ entre linhas; na safra 1999/2000, composta por cinco linhas de $8 \mathrm{~m}$ de comprimento, com o mesmo espaçamento. Foram aplicados durante o plantio $300 \mathrm{~kg} \mathrm{ha}^{-1}$ da fórmula NPK (5-30-15). Nos dois anos, as doses de N (30 e $\left.60 \mathrm{~kg} \mathrm{ha}^{-1}\right)$ foram aplicadas aos 20 dias após o plantio (DAP), na forma de sulfato de amônio. A primeira pulverização de fungicida foi feita na época da emissão das panículas e a segunda, com $10 \%$ das panículas emitidas, ou seja, aos 84 e 90 DAP no primeiro ano e aos 78 e 84 DAP no segundo ano, respectivamente. As pulverizações foram feitas com pulverizador costal de pressão controlada de 40 libras e volume de calda de $250 \mathrm{~L} \mathrm{ha}^{-1}$.

Os parâmetros avaliados consistiram da incidência e severidade da brusone nas folhas, na fase vegetativa, e nas panículas, durante a formação dos grãos, e produtividade, incluindo massa de grãos antes e depois de abanar.

Na safra 1998/1999, as amostras constituíram-se de 32, 20 e 16 perfilhos tomados ao acaso aos 55, 64 e 85 DAP, respectivamente. A incidência da brusone na folha foi medida contando-se o número de folhas com lesão em relação ao número total de folhas. A severidade da brusone nas folhas foi avaliada pelo número de lesões abertas nas três últimas folhas. Na safra 1999/2000, a incidência foi avaliada de forma semelhante à da safra anterior; a seve- 
ridade, tomando-se ao acaso 20 perfilhos, aos 48, 52, 55 e 59 DAP, e determinando-se a porcentagem da área foliar afetada pela doença nas últimas quatro folhas abertas, por meio de uma escala de 10 graus $(0 \%, 0,5 \%, 1 \%, 2 \%, 4 \%$, $8 \%, 16 \%, 32 \%, 64 \%$ e $82 \%$ de área foliar afetada), de acordo com Notteghem (1981).

A incidência da brusone nas panículas foi avaliada com base no número total de panículas coletadas em relação ao número de panículas com brusone no pescoço. A severidade da brusone nas panículas, nas duas safras, foi feita seguindo uma escala (Prabhu, 1990) com seis graus $(0 \%$, $5 \%, 25 \%, 50 \%, 75 \%$ e $100 \%$ de espiguetas afetadas/ panícula). A amostragem constituiu-se de todas as panículas das plantas contidas em $0,5 \mathrm{~m}$ de linha pré-marcada com duas estacas, nas duas linhas centrais de cada parcela.

Os dados de produção foram obtidos em área útil de $12,6 \mathrm{~m}^{2}$ e $0,7 \mathrm{~m}^{2}$ por parcela na safra 1998/1999 e 1999/ 2000 , respectivamente, eliminando-se as bordaduras.

Foi realizada a análise conjunta dos dois sistemas, por ano de experimento, considerando todas as variáveis. Os dados de incidência e severidade da brusone nas folhas e panículas (\%) foram transformados em arco seno $\sqrt{x / 100}$ e o número médio de lesões/folha em $\sqrt{x}$. A área sob a curva de progresso da doença (ASCPD) foi calculada de acordo com Shaner \& Finney (1977) e a análise de variância, transformando-se estes dados em $\log \mathrm{x}$. Realizou-se análise de correlação entre a incidência e a severidade da brusone nas folhas e nas panículas e a produtividade. Foram utilizadas 48 e 64 observações na análise no primeiro e no segundo ano, respectivamente.

\section{Resultados e Discussão}

A incidência e a severidade da brusone nas folhas foram superiores no PC, em ambos os anos de cultivo (Tabelas 1 e 2). Tal efeito, provavelmente, pode ser atribuído ao processo de imobilização do $\mathrm{N}$ por causa da maior concorrência deste nutriente no PD. De acordo com Weitholter (1997), no PD há maior perda de nitrato por lixiviação, menor decomposição dos restos culturais, pela maior volatilização da amônia e pela maior imobilização microbiana. A introdução de matéria orgânica com alta relação $\mathrm{C} / \mathrm{N}$ incrementa a atividade microbiana, aumentando a imobilização do $\mathrm{N}$ e, conseqüentemente, sua menor disponibilidade inicial às plantas (Santos et al., 1998). No PC, a maior disponibilidade de $\mathrm{N}$ propiciou elevada severidade da brusone comparativamente ao PD, mesmo com baixa incidência da brusone nos dois experimentos, o que é também justificado pelo aumento do período de suscetibilidade da planta (Zambolim \& Ventura, 1993). O sistema de plantio altera a atividade biológica do solo, afetando a liberação de nutrientes disponíveis às plantas, principalmente a disponibilidade de $\mathrm{N}$, que, em geral, é mais rápida no PC do que no PD (Sisterna \& Sarandón, 1996).

A correlação entre a incidência e a severidade da brusone foi positiva, sendo $r=0,88(\mathrm{P} \leq 0,001)$ e $\mathrm{r}=0,57(\mathrm{P} \leq 0,001)$ no primeiro e no segundo ano, respectivamente. Na safra 1998/1999, a ASCPD não diferiu quanto ao PD, porém na safra 1999/2000 foi altamente significativa, por causa do aumento da severidade da doença.

A cultivar Primavera apresentou incidência e severidade significativamente maiores que a Carajás, em todas as épocas de avaliação, indicando maior suscetibilidade à brusone nas folhas, em ambos os anos (Tabelas 1 e 2). As doses de $\mathrm{N}$ no primeiro ano agrícola não influenciaram significativamente a brusone nas folhas. Entretanto, no segundo ano, a dose de $60 \mathrm{~kg} \mathrm{ha}^{-1}$ de $\mathrm{N}$ aumentou significativamente a severidade, em todas as épocas de avaliação, e a ASCPD nas folhas, fato que pode ser atribuído às condições mais favoráveis ao desenvolvimento da doença, como época de semeadura e aumento do inóculo inicial no segundo ano. Prabhu et al. (1996), utilizando seis cultivares de arroz de sequeiro, constataram que a aplicação de $60 \mathrm{~kg} \mathrm{ha}^{-1}$ de $\mathrm{N}$ na semeadura, em geral, resultou em aumento da severidade da brusone nas folhas no PC. A adubação nitrogenada é um dos principais fatores do aumento da suscetibilidade das cultivares de arroz à brusone (Zambolim \& Ventura, 1993; Filippi \& Prabhu, 1998).

O tratamento das sementes com fungicida pyroquilon reduziu significativamente a incidência, a severidade e a ASCPD, nos dois anos de plantio, considerando a média dos dois sistemas de plantio em cada ano (Tabelas 1 e 2). Tais resultados estão de acordo com os obtidos por Prabhu \& Filippi (1993); Filippi \& Prabhu (1997) e Teixeira et al. (1997). A atividade residual do fungicida depende da pressão da doença e do grau de resistência da cultivar. O período de duração da proteção pelo fungicida pyroquilon variou entre 30 e 46 DAP nas cultivares suscetíveis, sob condições de alta pressão de doença (Prabhu \& Filippi, 1993). 
Dos três parâmetros de avaliação da brusone, verificou-se que o menor coeficiente de variação (CV) foi obtido pela ASCPD na quantificação da incidência e da severidade da doença. Resultados semelhantes foram obtidos por Prabhu et al.
(1996), os quais indicaram a necessidade de mais de uma variável para comparar e avaliar o lento progresso da brusone entre cultivares.

A severidade da brusone nas panículas foi superior no PC em comparação com o PD, nos dois anos

Tabela 1. Incidência, severidade e área sob curva de progresso (ASCPD) da brusone nas folhas em resposta ao plantio direto e convencional de arroz, cultivares, doses de nitrogênio e tratamento de sementes (1998/1999). Embrapa-CNPAF, Santo Antônio de Goiás, GO, 1999.

\begin{tabular}{|c|c|c|c|c|c|c|c|}
\hline \multirow[t]{2}{*}{ Variáveis } & \multicolumn{3}{|c|}{ Incidência $(\%)^{(1)}$} & \multicolumn{3}{|c|}{ Severidade $\left(\mathrm{n}^{\mathrm{o}} \text { de lesões por folha }\right)^{(2)}$} & \multirow[t]{2}{*}{$\mathrm{ASCPD}^{(3)}$} \\
\hline & $55 \mathrm{DAP}^{(4)}$ & 64 DAP & 85 DAP & 55 DAP & 64 DAP & 85 DAP & \\
\hline \multicolumn{8}{|l|}{ Sistema de plantio } \\
\hline Direto & 9,16 & 37,30 & 47,36 & 0,24 & 1,95 & 2,54 & 58,80 \\
\hline Convencional & 6,97 & 41,11 & 53,04 & 0,20 & 2,78 & 4,28 & 89,09 \\
\hline Teste F & $2,35^{\mathrm{ns}}$ & $1,41^{\mathrm{ns}}$ & $4,31 *$ & $0,29^{\mathrm{ns}}$ & $1,12^{\mathrm{ns}}$ & $30,95 * *$ & $3,34^{\mathrm{ns}}$ \\
\hline \multicolumn{8}{|l|}{ Cultivares } \\
\hline Carajás & 2,18 & 10,41 & 25,40 & 0,03 & 0,18 & 0,72 & 10,56 \\
\hline Primavera & 13,95 & 68,00 & 75,00 & 0,42 & 4,55 & 6,10 & 137,34 \\
\hline Teste F & $59,00 * *$ & $273,34 * *$ & $248,42 * *$ & $42,47 * *$ & $115,94 * *$ & $489,37 * *$ & $274,92 * *$ \\
\hline \multicolumn{8}{|c|}{ Doses de nitrogênio $\left(\mathrm{kg} \mathrm{ha}^{-1}\right)^{(5)}$} \\
\hline 30 & 6,40 & 36,53 & 42,57 & 0,13 & 2,19 & 2,70 & 68,49 \\
\hline 60 & 9,73 & 41,89 & 42,74 & 0,31 & 2,54 & 2,74 & 79,40 \\
\hline Teste F & $2,74^{\mathrm{ns}}$ & $2,62^{\mathrm{ns}}$ & $1,72^{\mathrm{ns}}$ & $2,88^{\mathrm{ns}}$ & $1,20^{\mathrm{ns}}$ & $2,08^{\mathrm{ns}}$ & $3,40^{\mathrm{ns}}$ \\
\hline \multicolumn{8}{|c|}{ Tratamento de sementes $\left(\mathrm{g} \mathrm{kg}^{-1} \text { de i.a. }\right)^{(6)}$} \\
\hline 0 & 10,67 & 43,78 & 52,16 & 0,35 & 2,73 & 3,66 & 83,49 \\
\hline 4 & 5,62 & 34,63 & 48,23 & 0,09 & 2,00 & 3,17 & 64,40 \\
\hline Teste F & $10,03 * *$ & $11,40 * *$ & $2,36^{\mathrm{ns}}$ & $11,43^{* *}$ & $4,40 *$ & $4,95 * *$ & $10,88^{* *} *$ \\
\hline CV (\%) & 44,29 & 22,67 & 15,13 & 65,54 & 45,19 & 16,04 & 16,90 \\
\hline
\end{tabular}

${ }^{(1)}$ Dados transformados em arco seno $(\mathrm{x} / 100)^{0,5}$. ${ }^{(2)}$ Dados transformados em $\mathrm{x}^{0,5}$. (3) Dados transformados em log x. ${ }^{(4)} \mathrm{DAP}=$ dias após o plantio

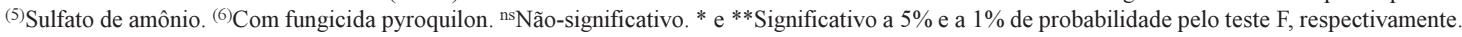

Tabela 2. Incidência, severidade e área sob curva de progresso (ASCPD) da brusone nas folhas em resposta ao plantio direto e convencional de arroz, cultivares, doses de nitrogênio e tratamento de sementes (1999/2000). Embrapa-CNPAF, Santo Antônio de Goiás, GO, 2000.

\begin{tabular}{|c|c|c|c|c|c|c|c|c|c|}
\hline \multirow[t]{2}{*}{ Variáveis } & \multicolumn{4}{|c|}{ Incidência $(\%)^{(1)}$} & \multicolumn{4}{|c|}{ Severidade $(\%)^{(1)}$} & \multirow[t]{2}{*}{$\mathrm{ASCPD}^{(2)}$} \\
\hline & $48 \mathrm{DAP}^{(3)}$ & 52 DAP & 55 DAP & 59 DAP & 48 DAP & 52 DAP & 55 DAP & 59 DAP & \\
\hline \multicolumn{10}{|l|}{ Sistema de plantio } \\
\hline Direto & 66,65 & 76,91 & 84,49 & 88,15 & 6,17 & 7,23 & 9,12 & 10,42 & 136,63 \\
\hline Convencional & 78,53 & 83,40 & 90,46 & 92,98 & 8,80 & 10,80 & 12,59 & 14,56 & 199,55 \\
\hline Teste F & $45,52 * *$ & $11,80 * *$ & $16,97 * *$ & $15,49 * *$ & $32,22 * *$ & $38,22 * *$ & $36,72 * *$ & $41,85^{* *}$ & $42,85^{* *}$ \\
\hline \multicolumn{10}{|l|}{ Cultivares } \\
\hline Carajás & 67,11 & 76,55 & 84,57 & 86,81 & 5,32 & 6,69 & 8,46 & 13,25 & 123,53 \\
\hline Primavera & 78,06 & 83,75 & 90,38 & 94,33 & 9,66 & 11,33 & 9,98 & 15,00 & 207,65 \\
\hline Teste F & $37,74 * *$ & $15,23 * *$ & $14,30 * *$ & $31,25 * *$ & $98,37 * *$ & $67,45 * *$ & $72,79 * *$ & $63,58 * *$ & $94,79 * *$ \\
\hline \multicolumn{10}{|c|}{ Doses de nitrogênio $\left(\mathrm{kg} \mathrm{ha}^{-1}\right)^{(4)}$} \\
\hline 30 & 73,57 & 79,44 & 87,71 & 90,41 & 6,86 & 8,02 & 9,68 & 11,29 & 149,71 \\
\hline 60 & 71,60 & 80,86 & 87,72 & 90,72 & 8,10 & 10,00 & 12,03 & 13,69 & 181,47 \\
\hline Teste F & $0,42^{\mathrm{ns}}$ & $0,41^{\mathrm{ns}}$ & $0,00^{\text {ns }}$ & $0,11^{\mathrm{ns}}$ & $10,82 * *$ & $11,58 * *$ & $17,46 * *$ & $14,71 * *$ & $14,62 * *$ \\
\hline \multicolumn{10}{|c|}{ Tratamento de sementes $\left(\mathrm{g} \mathrm{kg}^{-1} \text { de i.a. }\right)^{(5)}$} \\
\hline 0 & 78,54 & 83,56 & 89,26 & 92,17 & 8,86 & 10,77 & 12,94 & 14,86 & 196,87 \\
\hline 4 & 66,64 & 76,75 & 85,69 & 88,96 & 6,10 & 7,27 & 8,76 & 10,11 & 134,31 \\
\hline Teste F & $36,55^{* *}$ & 11,19 ** & $5,85^{*}$ & $6,95^{*}$ & $8,78 * *$ & $35,94 * *$ & $56,64 * *$ & $59,74 * *$ & $53,60 * *$ \\
\hline $\mathrm{CV}(\%)$ & 9,18 & 10,62 & 9,30 & 8,30 & 11,99 & 12,91 & 10,70 & 10,55 & 4,01 \\
\hline
\end{tabular}

${ }^{(1)}$ Dados transformados em arco seno $(\mathrm{x} / 100)^{0,5} .{ }^{(2)}$ Dados transformados em $\log \mathrm{x} .{ }^{(3)} \mathrm{DAP}=$ dias após o plantio. ${ }^{(4)}$ Sulfato de amônio. ${ }^{(5)}$ Com fungicida pyroquilon. nsNão-significativo. * e **Significativo a $5 \%$ e a $1 \%$ de probabilidade pelo teste $\mathrm{F}$, respectivamente. 
de plantio (Tabela 3). A cultivar Primavera foi mais meiro ano. No segundo ano, não foram observadas suscetível à brusone nas panículas do que a Carajás, diferenças significativas, por causa do plantio tarindependentemente do sistema de plantio, no pri- dio e das condições ambientais.

Tabela 3. Incidência e severidade da brusone nas panículas, massa de grãos antes de abanar (Produt. AA), massa de grãos depois de abanar (Produt. DA) e perda na massa de grãos, em resposta a plantio direto (PD) e convencional (PC) de arroz, cultivares, doses de nitrogênio e tratamento de sementes, nas safras de 1998/1999 e 1999/2000. EmbrapaCNPAF, Santo Antônio de Goiás, GO.

\begin{tabular}{|c|c|c|c|c|c|}
\hline Variáveis & $\begin{array}{l}\text { Incidência } \\
(\%)^{(1)}\end{array}$ & $\begin{array}{l}\text { Severidade } \\
(\%)^{(1)}\end{array}$ & $\begin{array}{l}\text { Produt. AA } \\
\left(\mathrm{kg} \mathrm{ha}^{-1}\right)\end{array}$ & $\begin{array}{l}\text { Produt. DA } \\
\left(\mathrm{kg} \mathrm{ha}^{-1}\right)\end{array}$ & $\begin{array}{l}\text { Perda } \\
(\%)^{(2)}\end{array}$ \\
\hline & & & $1998 / 1999$ & & \\
\hline \multicolumn{6}{|l|}{ Sistema de plantio } \\
\hline Direto & 4,22 & 12,58 & $1.493,44$ & $1.349,79$ & 11,00 \\
\hline Convencional & 6,48 & 20,29 & $2.042,97$ & $1.752,24$ & 18,00 \\
\hline Teste F & $0,07^{\mathrm{ns}}$ & $20,95 * *$ & $24,22 * *$ & $12,99 * *$ & $15,09 * *$ \\
\hline \multicolumn{6}{|l|}{ Cultivares } \\
\hline Carajás & 6,37 & 9,41 & $2.116,72$ & $1.954,17$ & 7,00 \\
\hline Primavera & 4,33 & 23,46 & $1.419,69$ & $1.147,86$ & 21,00 \\
\hline Teste F & $0,50^{\mathrm{ns}}$ & $72,42 * *$ & $38,96 * *$ & $52,13 * *$ & $62,02 * *$ \\
\hline \multicolumn{6}{|c|}{ Doses de nitrogênio $\left(\mathrm{kg} \mathrm{ha}^{-1}\right)^{(3)}$} \\
\hline 30 & 5,35 & 15,58 & $1.746,32$ & $1.538,38$ & 13,00 \\
\hline 60 & 5,35 & 17,29 & $1.790,09$ & $1.563,65$ & 15,00 \\
\hline Teste F & $0,31^{\mathrm{ns}}$ & $1,76^{\mathrm{ns}}$ & $0,15^{\mathrm{ns}}$ & $0,05^{\mathrm{ns}}$ & $1,58^{\mathrm{ns}}$ \\
\hline \multicolumn{6}{|c|}{ Tratamento de sementes $\left(\mathrm{g} \mathrm{kg}^{-1} \text { de i.a. }\right)^{(4)}$} \\
\hline 0 & 5,20 & 15,95 & $1.801,95$ & $1.595,44$ & 13,00 \\
\hline 4 & 5,21 & 16,92 & $1.734,46$ & $1.506,59$ & 14,00 \\
\hline Teste F & $0,49^{\mathrm{ns}}$ & $0,32^{\mathrm{ns}}$ & $0,37^{\mathrm{ns}}$ & $0,63^{\mathrm{ns}}$ & $0,10^{\mathrm{ns}}$ \\
\hline \multicolumn{6}{|l|}{ Pulverizações $\left(\mathrm{n}^{0}\right)^{(5)}$} \\
\hline 0 & 8,85 & 22,02 & $1.645,63$ & $1.418,99$ & 16,00 \\
\hline 2 & 1,86 & 10,85 & $1.890,77$ & $1.683,05$ & 12,00 \\
\hline Teste F & $53,63 * *$ & $49,77 * *$ & $22,43^{\text {ns }}$ & $27,39 * *$ & $12,8 * *$ \\
\hline \multirow[t]{2}{*}{$\mathrm{CV}(\%)$} & 66,23 & 30,15 & 14,34 & 15,94 & 4,97 \\
\hline & \multicolumn{5}{|c|}{$1999 / 2000$} \\
\hline \multicolumn{6}{|l|}{ Sistema de plantio } \\
\hline Direto & 0,84 & 8,02 & $1.146,17$ & 993,71 & 15,83 \\
\hline Convencional & 8,13 & 22,37 & $1.440,25$ & $1.214,93$ & 16,86 \\
\hline Teste F & $60,73 * *$ & $58,04 * *$ & $14,88^{* * *}$ & $8,82 *$ & $1,45^{\mathrm{ns}}$ \\
\hline \multicolumn{6}{|l|}{ Cultivares } \\
\hline Carajás & 4,49 & 14,96 & $1.457,37$ & $1.276,12$ & 13,44 \\
\hline Primavera & 4,49 & 15,43 & $1.129,05$ & 932,52 & 19,25 \\
\hline Teste $\mathrm{F}$ & $0,00^{\mathrm{ns}}$ & $0,23^{\text {ns }}$ & $18,54 * *$ & $21,28 * *$ & $28,50 * *$ \\
\hline \multicolumn{6}{|c|}{ Doses de nitrogênio $\left(\mathrm{kg} \mathrm{ha}^{-1}\right)^{(3)}$} \\
\hline 30 & 4,75 & 15,94 & $1.153,38$ & 974,02 & 17,53 \\
\hline 60 & 4,22 & 14,45 & $1.433,04$ & $1.234,62$ & 15,17 \\
\hline Teste F & $0,30^{\mathrm{ns}}$ & $0,41^{\mathrm{ns}}$ & $13,45^{* *}$ & $12,24 * *$ & $5,00 *$ \\
\hline \multicolumn{6}{|c|}{ Tratamento de sementes $\left(\mathrm{g} \mathrm{kg}^{-1} \text { de i.a. }\right)^{(4)}$} \\
\hline 0 & 4,24 & 16,86 & $1.256,09$ & $1.070,36$ & 16,56 \\
\hline 4 & 4,73 & 13,53 & $1.330,32$ & $1.182,19$ & 16,13 \\
\hline Teste F & $0,16^{\mathrm{ns}}$ & $48,75^{* *}$ & $0,95^{\mathrm{ns}}$ & $0,85^{\mathrm{ns}}$ & $0,16^{\text {ns }}$ \\
\hline \multicolumn{6}{|l|}{ Pulverizações $\left(\mathrm{n}^{\mathrm{o}}\right)$} \\
\hline 0 & 6,64 & 20,53 & $1.222,57$ & $1.026,45$ & 17,05 \\
\hline 2 & 2,33 & 9,86 & $1.363,85$ & $1.182,19$ & 15,65 \\
\hline Teste F & $28,57 * *$ & $48,75^{* *}$ & $14,27 * *$ & $18,35 * *$ & $5,90 *$ \\
\hline $\mathrm{CV}(\%)$ & 83,01 & 36,66 & 16,36 & 18,62 & 4,77 \\
\hline
\end{tabular}


Na safra de 1998/1999, a adubação nitrogenada e o tratamento das sementes não afetaram a incidência e a severidade da brusone nas panículas. Já na safra 1999/2000, o tratamento das sementes causou uma redução significativa na severidade da brusone nas panículas. Duas pulverizações na parte aérea, com as misturas dos fungicidas benomyl e difenoconazole, controlaram significativamente a brusone nas panículas, diminuindo a incidência e a severidade de $8,85 \%$ para $1,86 \%$ e de $22,02 \%$ para $10,85 \%$, respectivamente, na safra $1998 / 1999$, e de $6,64 \%$ para $2,33 \%$ e de $20,53 \%$ para $9,86 \%$, respectivamente, na safra 1999/2000 (Tabela 3). O benomyl mostrou-se eficiente no controle da brusone nas panículas de outras cultivares de arroz de terras altas e com doses menores que $500 \mathrm{~g} \mathrm{ha}^{-1}$ de i.a. (Prabhu et al., 1983). A correlação entre a severidade da brusone nas folhas e nas panículas foi positiva no primeiro ano $(\mathrm{r}=0,67, \mathrm{P} \leq 0,01)$ e baixa, embora significativa $(r=0,27, P \leq 0,05)$, no segundo ano.

A produtividade do arroz diferiu significativamente entre os sistemas de plantio, as cultivares e as pulverizações de fungicidas em ambos os anos (Tabela 3). De modo geral, os rendimentos decresceram da safra 1998/1999 para a de 1999/2000. A correlação entre a severidade da brusone nas folhas e a produtividade do arroz foi negativa e significativa $(\mathrm{r}=0,42, \mathrm{P} \leq 0,01)$ somente no primeiro ano. A brusone nas panículas, por sua vez, não afetou o rendimento nos dois anos. A produtividade do arroz foi superior no PC, em ambas as safras, apesar da maior severidade da brusone nas folhas e nas panículas, em relação ao $\mathrm{PD}$, indicando que os níveis da doença não afetaram a produtividade. A cultivar Carajás, por seu menor grau de suscetibilidade à brusone, obteve rendimento significativamente maior do que o da Primavera, independentemente do sistema de plantio.

As perdas na produtividade foram significativamente maiores no PC, com $18 \%$, contra $11 \%$ no PD, considerando o rendimento antes e depois de abanar. Tais resultados indicam indiretamente o efeito da brusone nas panículas no chochamento das espiguetas na safra 1998/1999; na safra 1999/2000, os resultados em relação às perdas não foram significativos. As perdas na produtividade foram meno- res na cultivar Carajás do que na Primavera. As duas pulverizações com fungicidas aumentaram significativamente a produtividade e diminuíram as perdas nos dois anos em que foram realizados os experimentos (Tabela 3). A resposta à aplicação do $\mathrm{N}$ em relação à produtividade foi significativa somente no segundo ano.

\section{Conclusões}

1. A incidência e a severidade da brusone são menores no plantio direto do que no plantio convencional.

2. Duas pulverizações com fungicidas controlam a brusone nas panículas.

3. A cultivar Carajás e o controle químico da brusone nas panículas são os principais componentes a serem incluídos no manejo integrado da brusone em arroz de terras altas, em plantio direto na palha do milheto.

\section{Agradecimentos}

À Funape-UFG, pela concessão da bolsa de mestrado ao primeiro autor; ao Sr. Pedro Maurício Machado, pela assistência na realização dos experimentos.

\section{Referências}

DERPSCH, R. Historical review of no tillage cultivation of crops. In: KOKUBUN, M. (Ed.). No tillage of soybean and future research needs in South America. Tsukuba: Japan International Research Center for Agricultural Sciences, 1998. p. 1-18. (Working Report, 13).

ENCONTROS nacionais de plantio direto impulsionaram o sistema. Revista Plantio Direto, Passo Fundo, n. 45, p. 12-16, maio/jun. 1998.

FERNANDES, F. T.; OLIVEIRA, E. de. Principais doenças na cultura do milho. Sete Lagoas: Embrapa CNPMS, 1997. 80 p. (Circular Técnica, 26).

FILIPPI, M. C.; PRABHU, A. S. Integrated effect of host plant resistance and fungicidal seed treatment on rice blast control in Brazil. Plant Disease, St. Paul, v. 81, n. 4, p. $351-355,1997$.

FILIPPI, M. C.; PRABHU, A. S. Relationship between panicle blast severity and mineral nutrient content of plant tissue in upland rice. Journal of Plant Nutrition, New York, v. 21, n. 8, p. 1577-1587, 1998. 
NOTTEGHEM, J. L. Cooperative experiment on horizontal resistance to rice blast. In: BLAST and upland rice: report and recommendation from the meeting for international collaboration in upland rice improvement. Los Baños: International Rice Research Institute, 1981. p. 43-51.

PRABHU, A. S. Mistura de cultivares no controle de brusone nas panículas em arroz de sequeiro. Pesquisa Agropecuária Brasileira, Brasília, v. 25, n. 8, p. 11831192, ago. 1990.

PRABHU, A. S.; FARIA, J. C.; CONTO, A. J.; CARVALHO, J. R. P. de. Resposta do arroz de sequeiro à aplicação de fungicida. Pesquisa Agropecuária Brasileira, Brasília, v. 18, n. 12, p. 1333-1340, dez. 1983.

PRABHU, A. S.; FILIPPI, M. C. Seed treatment with pyroquilon for the control of leaf blast in Brazilian upland rice. International Journal of Pest Management Hampshire, v. 39, n. 3, p. 347-353, 1993.

PRABHU, A. S.; FILIPPI, M. C.; ZIMMERMANN, F. J. P. Genetic control of blast in relation to nitrogen fertilization in upland rice. Pesquisa Agropecuária Brasileira, Brasília, v. 31, n. 5, p. 339-347, maio 1996.

REIS, E. M. Quantificação de propágulos de Giberela zeae no ar através de armadilhas de esporos. Fitopatologia Brasileira, Brasília, v. 13, n. 4, p. 324-327, 1988.

SANTOS, H. P.; REIS, E. M.; DERPSCH, R. Características agronômicas e controle de doença radiculares de trigo, em rotação com outras culturas de inverno. Pesquisa Agropecuária Brasileira, Brasília, v. 33, n. 3, p. 277-288, 1998

SHANER, G.; FINNEY, R. E. The effect of nitrogen fertilization on the expression of slow mildewing resistance in knox wheat. Phytopathology, St. Paul, v. 67, n. 8, p. 1051-1056, 1977.

SILVEIRA, P. M.; ZIMMERMANN, F. J. P.; AMARAL, A. M. Efeito da sucessão de cultura e do preparo do solo sobre o rendimento do arroz de sequeiro. Pesquisa Agropecuária Brasileira, Brasília, v. 33, n. 6, p. 885-890, jun. 1998.

SISTERNA, M. N.; SARANDÓN, S. J. Black point of wheat (Bipolares sorokiniana (Sacc) Shoem. influenced by $\mathrm{N}$ fertilization under no till and conventional tillage. Cereal Research Communications, Szeged, v. 24, n. 2, p. 217-221, 1996.

TEIXEIRA, E. L.; PRABHU, A. S.; FILIPPI, M. C. Eficiência relativa dos fungicidas sistêmicos, no tratamento de sementes para o controle da brusone nas folhas de arroz. Revista Brasileira de Sementes, Campinas, v. 19, n. 2, p. 180-185, 1997.

WIETHOLTER, S. Adubação nitrogenada para trigo cultivado após as culturas de soja e milho, em sistema de plantio direto. In: SEMINÁRIO INTERNACIONAL DO SISTEMA PLANTIO DIRETO, 2., 1997, Passo Fundo. Anais... Passo Fundo: Embrapa CNPT, 1997. p. 221-224.

YORINORI, J. T. Cancro da haste da soja: epidemiologia e controle. Londrina: Embrapa CNPSo, 1996. 75 p. (Circular Técnica, 14)

ZAMBOLIM, L.; VENTURA, J. A. Resistência a doença induzida pela nutrição mineral das plantas. Revisão Anual de Patologia de Plantas, Passo Fundo, v. 1, p. 275318, 1993. 